\title{
Original
}

\section{Differential Profile of OSA in Obese Kashmiri Patients of Northern India}

\author{
Javid Ahmad Malik', Sheikh Shoib², Bashir Ahmad Naikoo ${ }^{3}$, Shabir Ahmad Lone ${ }^{4}$, \\ Ramees Mohi Ud Din Mir ${ }^{5}$, Majid Khalil Rather ${ }^{6}$ \\ 1,4,5,6 Department of Pulmonary Medicine, SKIMS Medical College Bemina Srinagar \\ ${ }^{2}$ Department of Psychiatry, Government Medical College Srinagar, J \& K \\ ${ }^{3}$ Department of Cardiology, Government Medical College Srinagar, J \& K.
}

\section{A B S T R A C T}

Obstructive sleep apnea (OSA) and obesity are two interacting global epidemics both with high prevalence and morbidity. Both epidemiologic and clinical studies suggest that majority of patients with obesity also have OSA and untreated OSA in these patients results in significant cardiovascular and metabolic complications.

Objectives: To evaluate the profile of OSAin obese patients of Kashmir.

Methods: We performed polysomnography studies in obese patients that were referred from various sub-specialty clinics from July 2011 to August 2013.

Results: Out of 182 patients who underwent polysomnography (PSG), $110(60.4 \%)$ were obese (BMI > $30 \mathrm{~kg} / \mathrm{m} 2)$. In 110 obese patients, 104 $(94.5 \%)$ had OSA. Hypertension, diabetes and dyslipidemia were more prevalent among obese $(p<0.05)$. The mean neck circumference and mean BMI of obese patients was significantly more than that of non-obese $(33.9 \mathrm{~kg} / \mathrm{m} 2 \mathrm{vs}$. $26.8 \mathrm{~kg} / \mathrm{m} 2)(p<0.000)$. Presenting symptoms of obese were snoring $(97.3 \%)$, daytime sleepiness $(87.3 \%$ ) with a mean ESS of 15.3 , disturbed nocturnal sleep $(70.0 \%)$, nocturia $(62.7 \%)$ and witnessed apneas $(45.5 \%)$. OSA was significantly $(\mathrm{p}=0.002)$ more common among obese compared to non-obese $(93 \%$ vs $76 \%)$. Most were clinically suspected to have OSA by internists $(29 \%)$, cardiologists (20\%), endocrinologists (15\%) and psychiatrists (13\%). Sleep efficiency was significantly less $(p<0.03)$ in obese patients but sleep latency and REM sleep latency did not significantly differ between obese and non-obese. Unlike awake oxygen saturation the average nocturnal oxygen saturation of obese patients was significantly less [ $p=0.001$ ] than that of nonobese patients $(84.7 \%$ vs. $88.1 \%)$. The mean AHI of obese patients was significantly more than non-obese i.e $24.3 \mathrm{vs.} 18.0(p=0.001)$ and so was the mean ODI i.e 24.6 vs. $17.2(p=0.001)$. Variables that significantly correlated with presence of OSA include age, gender, BMI, hypertension, diabetes and cardiovascular disease $(p<0.05)$, however on logistic regression only BMI, hypertension, and nocturia correlated with OSA. CPAP therapy improved snoring, nocturia, nocturnal sleep and daytime sleepiness more in obese than non-obese OSA patients.

Conclusions: OSA which is highly prevalent among obese Kashmiri patients, is largely unrecognized in the primary care setting. It is associated with significant comorbidities and most of these improve with CPAP therapy. JMS 2016; 19(2):65-74.

Keywords: Obstructive sleep apnea, Obesity, CPAP.

\section{INTRODUCTION}

A substantial proportion of patients with obesity suffer from unrecognized obstructive sleep apnea (OSA) and conversely, obesity is more prevalent among OSA patients. OSA is a common sleep disorder affecting 10-20\% of the general population. ${ }^{1,2}$ A respiratory sleep-related disease, OSA is characterized by collapse of the pharynx in

\section{Correspondence \\ Dr. Javid Ahmad Malik, M.D.}

Associate Professor and Head, Department of

Pulmonary Medicine, SKIMS Medical College, Srinagar, India e-mail: javaidmalik2009@yahoo.co.in the face of persistent ineffective breathing efforts leading to repetitive interruptions of ventilation during sleep resulting in sleep fragmentation and arterial hypoxemia. OSA is characterized by upper airway obstructive during sleep, resulting in markedly reduced (hypopnea) or absent (apnea) airflow. OSA has been commonly associated with obesity, hypertension (HTN), type 2 diabetes mellitus (T2 DM), coronary artery disease (CAD), congestive heart failure $(\mathrm{CHF})$, atrial fibrillation (AF) and stroke. ${ }^{3-8}$ OSA not only increases long- term morbidity and mortality but has also been implicated in sudden nocturnal death. ${ }^{9,10}$ Few 
prospective studies have concluded that even habitual snoring independently increases the risk of $\mathrm{T}_{2} \mathrm{DM}^{11,12}$. A recent study suggested that mild oxyhemoglobin desaturation of less than $4 \%$ during sleep may predispose to fasting hyperglycemia. ${ }^{13}$ OSA has been reported as a highly prevalent comorbidity of T2DM by various authors ${ }^{14-16}$ and among obese patients with T2DM prevalence has recently been estimated at a staggering $86 \%$ in the United States ${ }^{17}$. In a recent prospective study of patients admitted with acute myocardial infarction (AMI) evaluated by overnight polysomnography (PSG), OSA was found to be significantly underdiagnosed ${ }^{17}$. Compared to stable outpatients, COPD patients who are admitted to the hospital with exacerbations have been found to have increased prevalence of OSA. ${ }^{18}$

Low awareness of OSA in obese patients among varoius admitting services, further compounds this problem. Given the gravity of this common but still under-diagnosed disorder, systematic evaluation and treatment of obese OSA patients is urgently required. Similarly the question whether OSA represents an independent risk for the development of pre-diabetes and T2DM over time also remains to be investigated by large prospective studies. It needs to be established firmly whether Continuous Positive Airway Pressure (CPAP) treatment of OSA improves various metabolic issues including glucose metabolism in obesity. Therefore the effective treatment of OSA with CPAP could potentially improve glucose control in millions of diabetics with OSA world over and thus has major clinical implications. Keeping this in mind we in the present study evaluated the profile of obese Kashmiri patients with OSA.

\section{METHODS}

Patients suspected of OSA who were referred for Polysomnography (PSG) from various sub-specialty clinics were recruited at Modern Hospital, Rajbagh, Srinagar between July 2011 to August 2013. Exclusion criteria were: 1) Patients on nocturnal oxygen supplementation; 2) Unstable Cardio-pulmonary, neurological, or psychiatric disease 3) Upper airway surgery 4) Using positive airway pressure therapy or oral appliances.

All participants gave written informed consent before PSG.

A detailed history of complaints including snoring, witnessed apneas, nocturia, disturbed nocturnal sleep and morning headaches was taken. Day time sleepiness was assessed by Epworth Sleepiness Scale (ESS). Height, weight and neck circumference were measured in all patients and body mass index (BMI) was calculated. An overnight laboratory PSG was then performed to diagnose the presence and severity of OSA. PSG recordings were started based on the subjects usual domestic sleeping habits and each patient was recorded for a minimum of 7 hours.

PSG included recordings of airflow by nasal pressure transducer and oronasal thermocouples, chest and abdominal wall motion by piezo electrodes, oxygen saturation by pulse oximeter, electrocardiogram, six electroencephalogram channels, bilateral electrooculograms, chin and tibialis electromyogram. Recordings were scored visually in 30 seconds in Non-REM sleep stages 1-4 sleep and in REM sleep according to standard criteria $^{19}$. Similarly respiratory events and microarousals were scored according to established criteria ${ }^{20,21}$. Complete cessation of airflow for at least 10 seconds was defined as apnea (obstructive if respiratory efforts were present and central if respiratory efforts were absent) and hypopnea was identified if there was a discernable reduction in airflow lasting at least 10 seconds and associated with at least 3\% oxygen desaturation. The apnea hypopnea index (AHI) was defined as the total number of obstructive apneas and hypopneas per hour of sleep. Oxygen desaturation index (ODI) was defined as the total number of desaturations of at least 3\% per total sleep time in hours. We defined OSA severity categories according to commonly used clinical cutoffs i.e., No OSA (AHI $<5$ ); Mild OSA (AHI $\geq 5$ but $<15$ ); Moderate OSA (AHI $\geq 15$ but $<30$ ); and Severe OSA (AHI $\geq 30$ ).

\section{Statistical Analysis:}

Standard methods of statistical analysis were used for data analysis. After descriptive statistical analysis of the general characteristics of the study participants, the KolmogorovSmirnov test was used to examine the distribution of variables, and the Levene test to study the variance. Qualitative variables were analyzed with the $\chi^{2}$ test or with Fisher's exact test if at least one cell had an expected count $<5$. Student's t-test was applied to compare 
mean values of quantitative variables when the distribution was normal and the MannWhitney $U$ test when it was not. For paired samples the Student's t- test for paired samples and Mc Nemar test were used. Pearson's coefficient was used to test the correlation between quantitative variables; $p$ $\leq 0.05$ was considered significant. SPSS 11.0 was used for data analyses (SPSS Inc., Chicago, IL, USA).

\section{RESULTS}

Out of 182 patients who underwent polysomnography, 110 $(60.44 \%)$ were obese $($ BMI $>30 \mathrm{~kg} / \mathrm{m} 2)$ including 50 $(45.5 \%)$ males and $60(54.5 \%)$ females $(p>0.5)$. Out of 110 obese patients, $104(94.5 \%)$ had abnormal test and only 6 (5.5\%) had normal PSG. The mean age (Table 1) was not significantly different between obese and non-obese subjects $(54.9 \mathrm{vs}$

55.5 years). Comorbidities like hypertension, T2DM and dyslipidemia were more prevalent among obese compared to non-obese patients $(\mathrm{p}<0.05)$. However other comorbidities like hypothyroidism, cardiovascular disease and COPD did not differ among the obese and non-obese in the study population ( $p>0.05$ ). Mean BMI (Table 2) of obese patients was significantly more than that of non-obese patients $(33.9 \mathrm{~kg} / \mathrm{m} 2$ vs. $26.8 \mathrm{~kg} / \mathrm{m} 2)(\mathrm{p}<0.000)$ and so was the mean neck circumference ( 40.9 vs $39.3 \mathrm{cms})(\mathrm{p}<0.002)$.

The main presenting symptoms of obese patients were snoring 107 (97.3\%), daytime sleepiness 96 (87.3\%) with a mean ESS of 15.3, disturbed nocturnal sleep 77 (70.0\%), nocturia $69(62.7 \%)$ and witnessed apneas 50 (45.5\%). All these symptoms were more common in obese compared to non- obese patients (Table 3 ). There was no significant difference in sleepiness between obese and non-obese whose mean ESS was 15.3 and 14.4 respectively $(\mathrm{p}>0.5)$. There were few atypical presentations in our study that included nocturnal enuresis and night terrors for two years in a 38 year obese male, a 55 year businessman felt asleep while going for a morning walk and slipped into a drain and a near fatal road traffic accident when a retired engineer dozed off while driving his car. OSA was significantly ( $p=0.002$ ) more common among obese compared to nonobese individuals (93\% vs $76 \%$ ). Clinically most of these patients were initially suspected to have OSA by internists (29\%), cardiologists $(20 \%)$, endocrinologists (15\%) and psychiatrists (13\%) before referring them for polysomnography (Table 4).

Sleep efficiency (Table 5) was significantly less $(\mathrm{p}<0.03)$ in obese patients (mean $71.0 \%$ ) as compared to non-obese (mean 74.0\%). Mean Sleep latency did not significantly differ ( $\mathrm{p}=0.41)$ between obese and non-obese patients (21.6 vs 20.5 minutes). Like sleep latency, mean REM sleep latency also did not significantly differ among obese and non-obese (74.3 vs 75.2 minutes) [ $p=0.66]$. Mean room air awake oxygen saturation ( $\mathrm{SpO} 2$ ) did not significantly differ between obese and non-obese patients (92.7\% vs 93.9\%) $[\mathrm{p}=0.053]$. Unlike awake oxygen saturation the average nocturnal oxygen saturation of obese patients was significantly less $[\mathrm{p}=0.001]$ than that of non-obese patients (84.7\% vs. $88.1 \%$ ). The mean AHI of obese patients was significantly more than non-obese patients i.e 24.3 vs. 18.0 $(\mathrm{p}=0.001)$. The mean ODI of obese patients was significantly more than non-obese i.e 24.6 vs. 17.2 ( $\mathrm{p}=$ $0.001)$. Variables that significantly correlated with presence of OSA include age, gender, BMI, hypertension, diabetes and cardiovascular disease $(\mathrm{p}<0.05)$, however on logistic regression only BMI, hypertension, and nocturia correlated with OSA.

CPAP therapy improved snoring in both obese as well as non-obese OSA patients, however there was no significant difference between the two groups $(p=0.663)$ in terms of response category (Table 6). Like snoring, CPAP therapy also improved nocturia, nocturnal sleep and daytime sleepiness in both obese and non-obese OSA patients, however the overall improvement was more in obese compared to non-obese subjects.

\section{DISCUSSION}

Obstructive sleep apnea (OSA) is underrecognized globally and as obesity relentlessly increases so does OSA. This may be partially explained by the lack of awareness of OSA even in hospitalized settings as is illustrated by the minimal documentation of prior OSA history by resident doctors and limited referrals for OSA evaluation. Recognizing this condition in a timely and efficient manner may lead to fewer readmissions and ultimately reduce costs for at-risk population. ${ }^{22}$ Usual risk factors that are independently associated with high risk for OSA include high BMI, male 
sex, CAD, CHF, and COPD. OSA has significant cardiovascular implications and is associated with sudden death. ${ }^{23}$ Although once thought to be independent diseases, the high prevalence of OSA among obese diabetics ${ }^{24}$ and vice versa ${ }^{25}$ has raised interesting questions as to how OSA and diabetes interact. Untreated OSA is associated with poor glycemic control resulting in intensification of pharmacotherapy that promotes weight gain and further exacerbates the severity of existing OSA thereby elevating cardiovascular risk. OSA is characterized by recurrent upper airway occlusions during sleep that result in specific physiologic disturbances, including sleep fragmentation and chronic intermittent hypoxia. These disturbances lead to a cascade of events related to the activation of the sympathoadrenal system, oxidative stress, systemic inflammation, and changes in adipokines all of which are important in increasing the risk of hypertension, cardiovascular disease, metabolic syndrome, and diabetes 26,27. Enough evidence has been found that supports the hypothesis that OSA and the resultant intermittent hypoxia, elevated sympathetic nervous activity, sleep fragmentation, less amount of slow wave sleep and cumulative sleep loss has adverse effects on glucose tolerance. ${ }^{28}$ Chronic sleep loss, a consequence of OSA, is associated with decreased glucose tolerance, decreased leptin, and an increase in evening cortisol levels. Both adipose tissue and diabetes are associated with immune activation and subsequent increase in the circulating pro-inflammatory cytokines, which in turn play a role in the pathogenesis of OSA ${ }^{29}$. In the present study nearly $95 \%$ obese patients had OSA indicating that OSA is a highly prevalent comorbidity in obese Kashmiri patients.

Another important observation of our study was that compared to non- obese the average nocturnal oxygen saturation of obese patients was significantly less. Pulse oximetry can be a key to appropriate use of polysomnography by identifying patients most likely to have an uninterpretable test i.e severe insomnia, high oxygen requirement, excruciating pain, altered mental status, frequent anticipated disturbances during the night, and severe restless legs syndrome. Under these circumstances the standardization of pulse oximetry is essential to facilitate agreement with polysomnography and an ODI $\geq 15 / \mathrm{h}$ essentially rules out false positive diagnoses and can be a cost-effective tool particularly in resource limited regions like Kashmir.

CPAP (continuous positive airway pressure) a nonpharmacological intervention which is the goldstandard treatment of OSA, is highly effective in relieving the symptoms of OSA. In one of our recent studies ${ }^{30}$ we demonstrated the positive impact of CPAP in the management of blood glucose control as reflected by decline in HbA1c levels in 59\% of Kashmiri diabetic patients. A reduction in $\mathrm{HbAl}$ c level has been shown to be associated with a reduction in the risk of macrovascular and microvascular complications associated with diabetes. ${ }^{31,32} \mathrm{In}$ addition to improvement in blood glucose, CPAP therapy also resulted in improvement in blood pressure of as many as $75 \%$ of our patients. This dual benefit of positive impact on blood sugar and blood pressure by CPAP treatment may potentially help globally millions of patients with OSA. One of the earliest studies was that of Brooks et $\mathrm{al}^{33}$ who investigated the insulin responsiveness before and during CPAP in 10 very obese OSA patients. CPAP significantly improved insulin responsiveness in those patients within 4 months of treatment. In a comparable study, Harsch et al 34 also have reported improvement in insulin sensitivity in obese diabetics with CPAP therapy. The effect, however, was seen after 3 months of CPAP and not immediately like that in non-obese non-diabetics. ${ }^{35}$

Clinician has to carefully examine the associations between OSA severity and metabolic variables. It is also important to obtain polysomnographic recordings and administer subsequent CPAP therapy for longer than the commonly used minimum of 4 hours.

Though CPAP adherence is fundamental to OSA therapy, we should not ignore that the benefits of CPAP may not be the same for cognitive and metabolic outcomes. Our earlier study has demonstrates that CPAP treatment not only improves glycemic control in a significant number of OSA patients but it also improves their cognitive function ${ }^{30}$.

\section{CONCLUSION}

The findings of our study suggest that OSA is highly prevalent among obese Kashmiri patients and is largely unrecognized in the primary care setting. Most of the 
clinicians do not suspect OSA in the beginning resulting in delayed diagnosis. Thus the role of OSA in the management of obesity is in urgent need of further assessment and current practice approaches should be modified to include systematic evaluation and treatment of OSA.

TABLE 1: Demographic characteristics of the Study population, obese vs. non-obese

\begin{tabular}{|c|c|c|c|c|c|}
\hline \multicolumn{2}{|c|}{ Demographic characteristic } & $\begin{array}{c}\text { Non Obese } \\
(n=72)\end{array}$ & $\begin{array}{c}\text { Obese } \\
(n=110)\end{array}$ & $\begin{array}{c}\text { Total } \\
(n=182)\end{array}$ & $\begin{array}{c}P \\
\text { value }\end{array}$ \\
\hline \multirow{7}{*}{ Age(Years) } & $\begin{array}{l}\text { Mean } \pm \text { SD } \\
\text { (Range) }\end{array}$ & $\begin{array}{l}55.5 \pm 12.8 \\
(30-85)\end{array}$ & $\begin{array}{l}54.5 \pm 13.0 \\
(22-90)\end{array}$ & $\begin{array}{l}54.9 \pm 12.9 \\
(22-90)\end{array}$ & 0.591 \\
\hline & $<30 y$ & $0,0.0 \%$ & $4,3.6 \%$ & $4,2.2 \%$ & \multirow{6}{*}{0.144} \\
\hline & $30-39$ & $11,15.3 \%$ & $7,6.4 \%$ & $18,9.9 \%$ & \\
\hline & $40-49$ & $13,18.1 \%$ & $30,27.3 \%$ & $43,23.6 \%$ & \\
\hline & $50-59$ & $21,29.2 \%$ & $26,23.6 \%$ & $47,25.8 \%$ & \\
\hline & $60-69$ & $15,20.8 \%$ & $24,21.8 \%$ & $39,21.4 \%$ & \\
\hline & $\geq 70 y$ & $12,16.7 \%$ & $19,17.3 \%$ & $31,17.0 \%$ & \\
\hline Female gender & $\mathrm{N}, \%$ & $35,48.6 \%$ & $60,54.5 \%$ & $95,52.2 \%$ & 0.433 \\
\hline Hypertension & $N, \%$ & $41,56.9 \%$ & $80,72.7 \%$ & $121,66.5 \%$ & $0.027^{*}$ \\
\hline Diabetics & $N, \%$ & $18,25.0 \%$ & $44,40.0 \%$ & $62,34.1 \%$ & $0.037^{*}$ \\
\hline Hypothyroidism & $\mathrm{N}, \%$ & $23,31.9 \%$ & $40,36.4 \%$ & $63,34.6 \%$ & 0.054 \\
\hline CVD & $N, \%$ & $7,9.7 \%$ & $21,19.1 \%$ & $28,15.4 \%$ & 0.087 \\
\hline Dyslipidemia & $N, \%$ & $4,5.6 \%$ & $22,20.0 \%$ & $26,14.3 \%$ & $0.006^{*}$ \\
\hline $\begin{array}{l}\text { COPD/ } \\
\text { Asthama }\end{array}$ & $N, \%$ & $10,13.9 \%$ & $14,12.7 \%$ & $24,13.2 \%$ & 0.821 \\
\hline
\end{tabular}

TABLE 2: Anthropometric characteristics of the Study population, obese vs. non- obese

\begin{tabular}{|c|c|c|c|c|c|}
\hline \multicolumn{2}{|c|}{ Variable } & $\begin{array}{l}\text { Non Obese } \\
\qquad(\mathrm{n}=72)\end{array}$ & $\begin{array}{l}\text { Obese } \\
(n=110)\end{array}$ & $\begin{array}{c}\text { Total } \\
(n=182)\end{array}$ & $\begin{array}{c}\mathrm{P} \\
\text { value }\end{array}$ \\
\hline BMI & $\begin{array}{c}\text { Mean } \pm \text { SD } \\
\text { (Range) }\end{array}$ & $\begin{array}{c}26.8 \pm 2.1 \\
(21-29)\end{array}$ & $\begin{array}{c}33.9 \pm 3.5 \\
(30-49)\end{array}$ & $\begin{array}{c}31.1 \pm 4.6 \\
(21-49)\end{array}$ & $0.000^{*}$ \\
\hline \multirow{4}{*}{$\begin{array}{l}\text { Neck } \\
\text { circum }\end{array}$} & $\begin{array}{c}\text { Mean } \pm \text { SD } \\
\text { (Range) }\end{array}$ & $\begin{array}{c}39.3 \pm 2.9 \\
(34-46)\end{array}$ & $\begin{array}{c}40.9 \pm 3.6 \\
(33-50)\end{array}$ & $\begin{array}{c}40.3 \pm 3.4 \\
(33-50)\end{array}$ & $0.002^{*}$ \\
\hline & $>=47 \mathrm{~cm}$ & $0,0.0 \%$ & $5,4.5 \%$ & $5,2.7 \%$ & \\
\hline & $37-47 \mathrm{~cm}$ & $59,81.9 \%$ & $93,84.5 \%$ & $152,83.5 \%$ & 0.085 \\
\hline & $<37 \mathrm{~cm}$ & $13,18.1 \%$ & $12,10.9 \%$ & $25,13.7 \%$ & \\
\hline
\end{tabular}


TABLE 3: OSA features of the Study population, obese vs. non-obese

\begin{tabular}{|c|c|c|c|c|}
\hline & \multicolumn{2}{|c|}{ Obese $(\mathrm{BMI}>30)$} & \multirow[b]{2}{*}{ Total } & \multirow[b]{2}{*}{$P$ value } \\
\hline & No & Yes & & \\
\hline Co-Morbidity & $\begin{array}{l}10 \\
13.9 \%\end{array}$ & $\begin{array}{l}16 \\
14.5 \%\end{array}$ & $\begin{array}{l}26 \\
14.3 \%\end{array}$ & 0.901 \\
\hline Snoring & $\begin{array}{l}66 \\
91.7 \%\end{array}$ & $\begin{array}{l}107 \\
97.3 \%\end{array}$ & $\begin{array}{l}173 \\
95.1 \%\end{array}$ & 0.088 \\
\hline Witnessed Apneas & $\begin{array}{l}23 \\
31.9 \%\end{array}$ & $\begin{array}{l}50 \\
45.5 \%\end{array}$ & $\begin{array}{l}73 \\
40.1 \%\end{array}$ & 0.069 \\
\hline Nocturia & $\begin{array}{l}39 \\
54.2 \%\end{array}$ & $\begin{array}{l}69 \\
62.7 \%\end{array}$ & $\begin{array}{l}108 \\
59.3 \%\end{array}$ & 0.250 \\
\hline Disturbed sleep & $\begin{array}{l}44 \\
61.1 \%\end{array}$ & $\begin{array}{l}77 \\
70.0 \%\end{array}$ & $\begin{array}{l}121 \\
66.5 \%\end{array}$ & 0.214 \\
\hline Daytime Sleepiness & $\begin{array}{l}57 \\
79.2 \%\end{array}$ & $\begin{array}{l}96 \\
87.3 \%\end{array}$ & $\begin{array}{l}153 \\
84.1 \%\end{array}$ & 0.144 \\
\hline OSA & $\begin{array}{l}55 \\
76.4 \%\end{array}$ & $\begin{array}{l}102 \\
92.7 \%\end{array}$ & $\begin{array}{l}157 \\
86.3 \%\end{array}$ & $0.002^{*}$ \\
\hline OSA Severity & 16 & 45 & 61 & \\
\hline o Severe & $\begin{array}{l}16 \\
29.1 \%\end{array}$ & $\begin{array}{l}45 \\
44.1 \%\end{array}$ & $\begin{array}{l}61 \\
38.9 \%\end{array}$ & \\
\hline o Moderate & $\begin{array}{l}26 \\
47.3 \%\end{array}$ & $\begin{array}{l}43 \\
42.2 \%\end{array}$ & $\begin{array}{l}69 \\
43.9 \%\end{array}$ & 0.115 \\
\hline o Mild & $\begin{array}{l}13 \\
23.6 \%\end{array}$ & $\begin{array}{l}14 \\
13.7 \%\end{array}$ & $\begin{array}{l}27 \\
17.2 \%\end{array}$ & \\
\hline
\end{tabular}

TABLE 4 : Clinical suspicion of OSA specialty-wise, obese vs. non-obese

\begin{tabular}{|c|c|c|c|}
\hline \multirow{2}{*}{ Referred by } & \multicolumn{2}{|c|}{ Obese $(\mathrm{BMI}>30)$} & \multirow{2}{*}{ Total } \\
\hline & No & Yes & \\
\hline Pulmonologist & $04, \quad 5.6 \%$ & $05, \quad 4.5 \%$ & $09, \quad 4.9 \%$ \\
\hline Psychiatrist & $12, \quad 16.7 \%$ & $14, \quad 12.7 \%$ & $26, \quad 14.3 \%$ \\
\hline Neurologist & $05, \quad 6.9 \%$ & $06, \quad 5.5 \%$ & $11, \quad 6.0 \%$ \\
\hline Nephrologist & $5.6 \%$ & $3.6 \%$ & $4.4 \%$ \\
\hline Internist & $20, \quad 27.8 \%$ & $32, \quad 29.1 \%$ & $52, \quad 28.6 \%$ \\
\hline Gen. surgeon & $03, \quad 4.2 \%$ & $03, \quad 2.7 \%$ & $06, \quad 3.3 \%$ \\
\hline ENT surgeon & $5.6 \%$ & $5.5 \%$ & $5.5 \%$ \\
\hline Endocrinologist & $10, \quad 13.9 \%$ & $17, \quad 15.5 \%$ & $27, \quad 14.8 \%$ \\
\hline Cardiologist & $10, \quad 3.9 \%$ & $22, \quad 20.0 \%$ & $32, \quad 17.6 \%$ \\
\hline Anaesthetist & $0.0 \%$ & $01, \quad 0.9 \%$ & $01, \quad 0.5 \%$ \\
\hline$=0.963$ & & & \\
\hline
\end{tabular}


TABLE 5 : PSG characteristics of the Study population, obese vs. non-obese

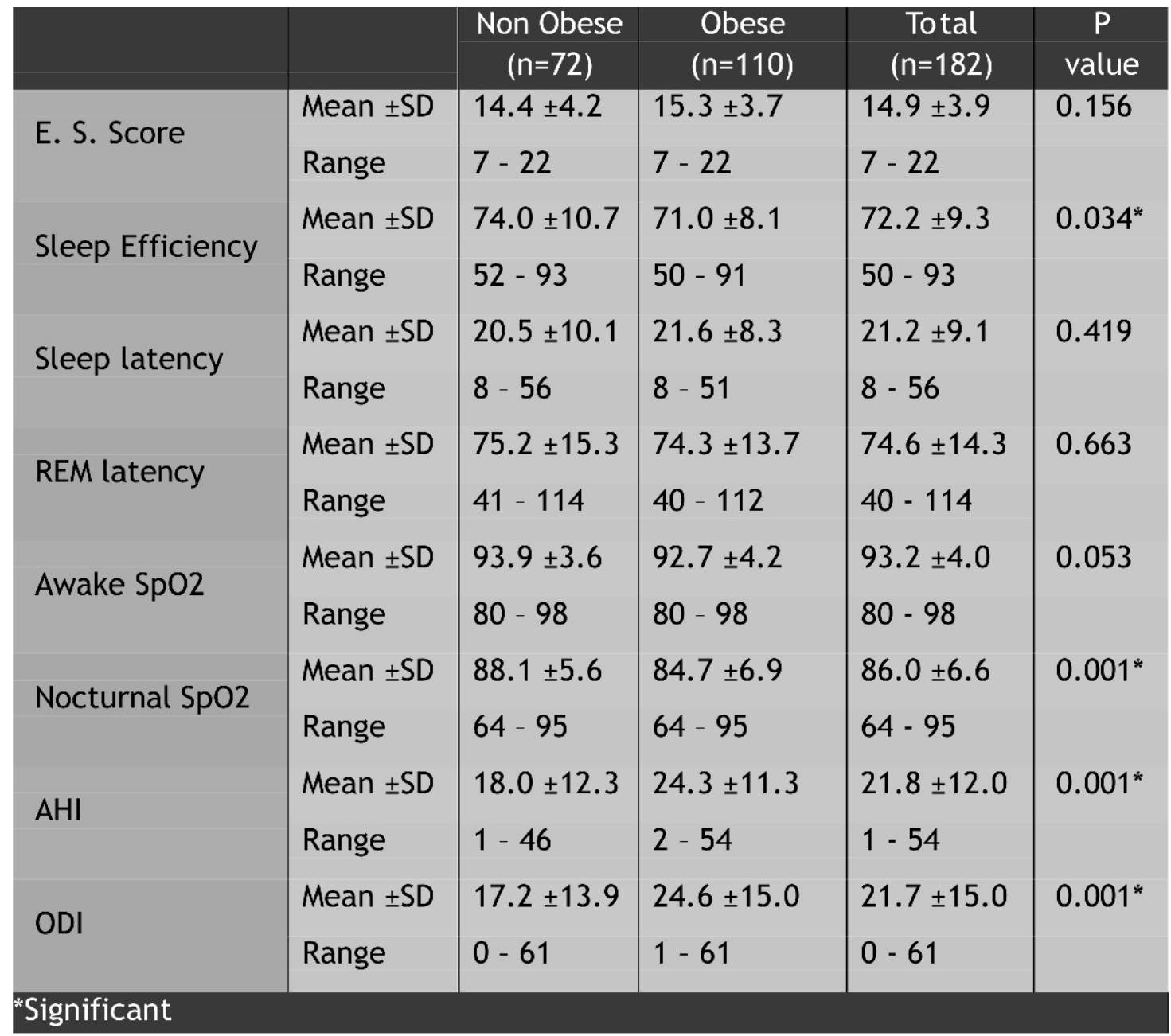

TABLE 6 : Effect of CPAP therapy, obese vs. non-obese

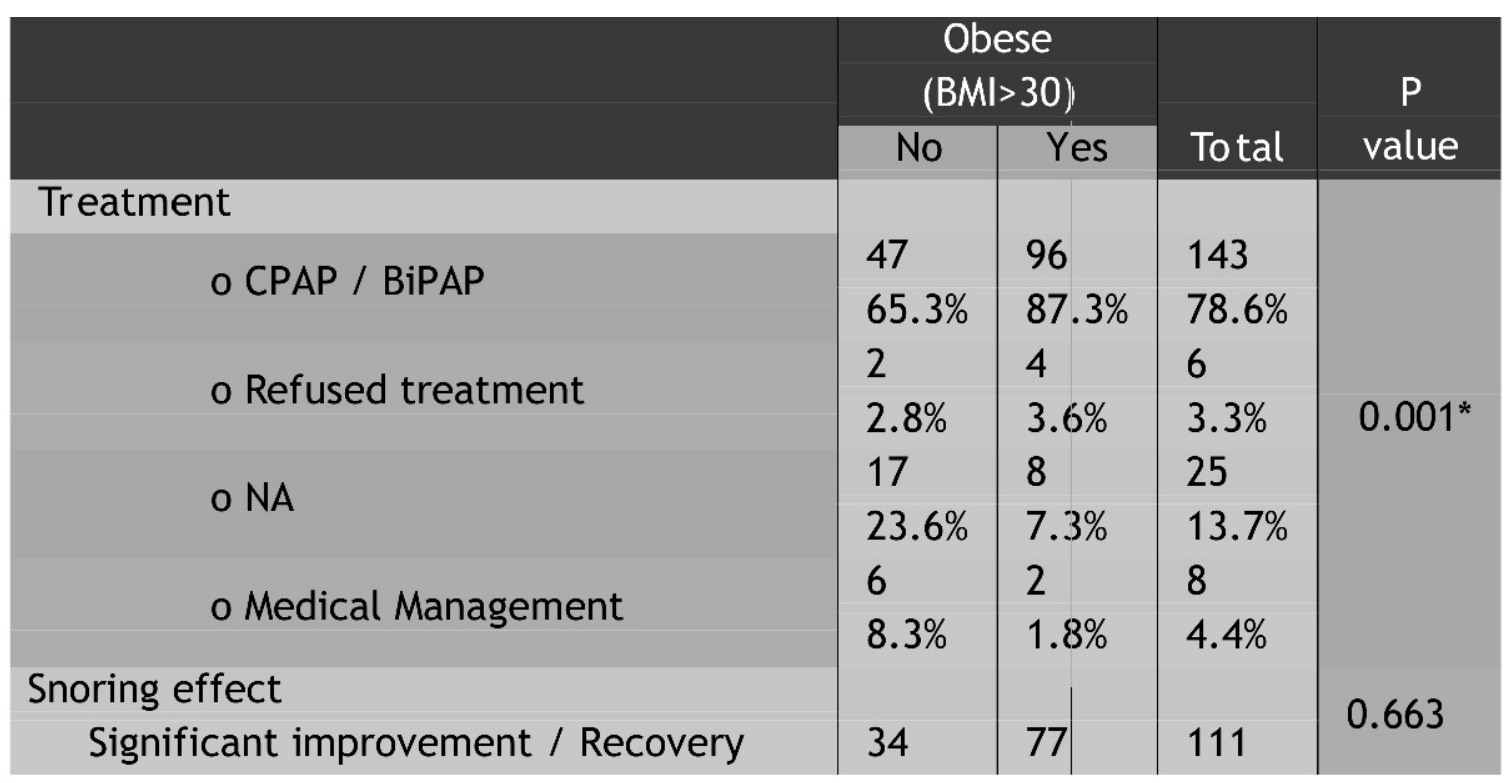




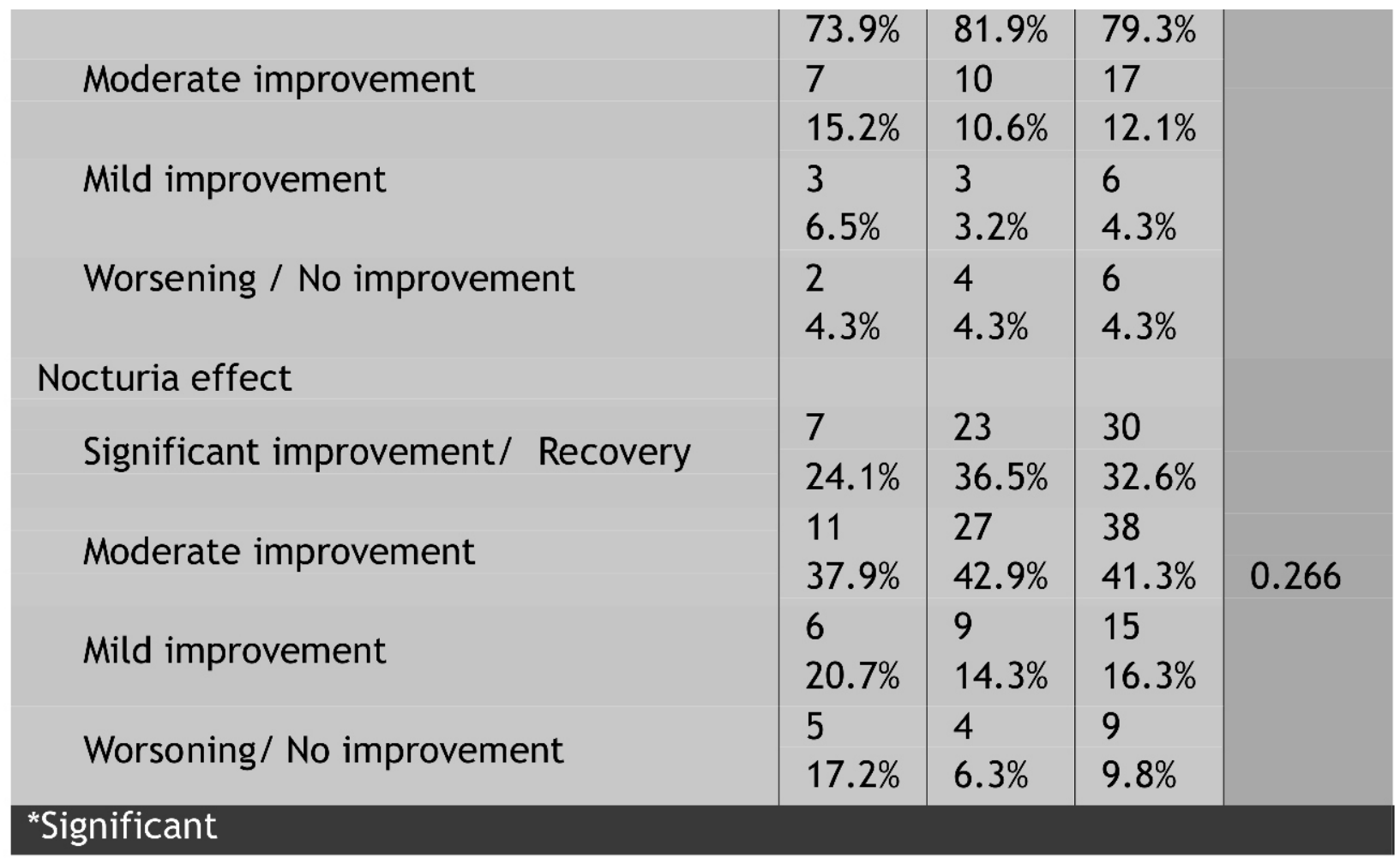




\section{REFERENCES}

1. Peppard PE, Young T, Barnet JH, Palta M, Hagen EW, Hla KM. Increased prevalence of sleep- disordered breathing in adults. Am J Epidemiol 2013;177:100614.

2. Young T, Palta M, Dempsey J, Peppard PE, Nieto FJ, Hla KM. Burden of sleep apnea: rationale, design, and major findings of the Wisconsin Sleep Cohort study. WMJ 2009;108:2469.

3. Sin DD, Fitzgerald F, Parker JD, Newton G, Floras J, Bradley TD. Risk factors for central and obstructive sleep apnea in 450 men and women with congestive heart failure. Am J Respir Crit Care Med 1999;160:11016.

4. Gami AS, Hodge DO, Herges RM, Olson EJ, Nykodym J, Kara T, Somers VK. Obstructive sleep apnea, obesity, and the risk of incidence atrial fibrillation. JAm Coll Cardiol 2007;49:56571.

5. Javaheri S, Parker TJ, Liming JD, Corbett WS, Nishiyama H, Wexler L, Roselle GA. Sleep apnea in 81 ambulatory male patients with stable heart failure. Circulation 1998; 97:21549.

6. Peppard PE, Young T, Palta M, Skatrud J. Prospective study of the association between sleep- disordered breathing and hypertension. N Engl J Med 2000; 342:137884.

7. Gottlieb DJ, Yenokyan G, Newman AB, O'Connor GT, Punjabi NM, Quan SF, Redline S, Resnick HE, Tong EK, Diener-West M, Shahar E. Prospective study of obstructive sleep apnea and incident coronary heart disease and heart failure: the Sleep Heart Health Study. Circulation 2010; 122:35260.

8. Arzt M, Young T, Finn L, Skatrud JB, Bradley TD. Association of sleep- disordered breathing and the occurrence of stroke. Am J Respir Crit Care Med $2005 ; 172: 144751$.

9. Gami AS, Olson EJ, Shen WK, Wright RS, Ballman KV, Hodge DO, Herges RM, Howard DE, Somers VK. Obstructive sleep apnea and the risk of sudden cardiac death: a longitudinal study of 10,701 adults. J Am Coll Cardiol 2013; 62:6106.

10. Garcia-Touchard A, Somers VK, Kara T, Nykodym J, Shamsuzzaman A, Lanfranchi P, Ackerman MJ. Ventricular ectopy during REM sleep: implications for nocturnal sudden cardiac death. Nat Clin Pract Cardiol 2007; 4:2848.

11. Elmasry A, Janson C, Lindberg E, Gislason T, Tageldin MA, Boman G. The role of habitual snoring and obesity in the development of diabetes: a 10-year follow-up study in a male population. J Intern Med 2000; 248:1320.

12. Al-Delaimy WK, Manson JE, Willett WC, Stampfer $\mathrm{MJ}, \mathrm{Hu} \mathrm{FB}$. Snoring as a risk factor for type II diabetes mellitus: a prospective study. Am J Epidemiol 2002; 155:38793.

13. Stamatakis K, Sanders MH, Caffo B, Resnick HE, Gottlieb DJ, Mehra R, Punjabi NM. Fasting glycemia in sleep disordered breathing: lowering the threshold on oxyhemoglobin desaturation. Sleep 2008; 31:1018 24.

14. Resnick HE, Redline S, Shahar E, Gilpin A, Newman A, Walter R, Ewy GA, Howard BV, Punjabi NM. Diabetes and sleep disturbances: findings from the Sleep Heart Health Study. Diabetes Care 2003; 26:702 709 .

15. Einhorn D, Stewart DA, Erman MK, Gordon N, Philis-Tsimikas A, Casal E. Prevalence of sleep apnea in a population of adults with type 2 diabetes mellitus. Endocr Pract 2007; 13:355362.

16. Foster GD, Sanders MH, Millman R, Zammit G, Borradaile KE, Newman AB, Wadden TA, Kelley D, Wing RR, Sunyer FX, Darcey V, Kuna ST; Sleep AHEAD Research Group. Obstructive sleep apnea among obese patients with type 2 diabetes. Diabetes Care 2009; 32(6):1017-9.

17. Konecny T, Sert-Kuniyoshi FH, Orban M, Pressman GS, Kara T, Gami A, Caples SM, Lopez-Jimenez F, Somers VK. Under-diagnosis of sleep apnea in patients after acute myocardial infarction. J Am Coll Cardiol 2010; 56:7423.

18. Turcani P, Skrickova J, Pavlik T, Janousova E, Orban M. The prevalence of obstructive sleep apnea in patients hospitalized for COPD exacerbation. Biomed Pap Med Fac Univ Palacky Olomouc Czech Repub. 2015; 159(3):422-8.

19. Rechtschaffen A, Kales A. A manual of standardized terminology, techniques and scoring system for sleep stages of human subjects. Los Angeles: UCLA Brain 
Information Service / Brain Research Institute 1968.

20. EEG arousals: scoring rules and examples: a preliminary report from the Sleep Disorders Atlas Task Force of the American Sleep Disorders Association. Sleep 1992; 15:173184.

21. Sleep-related breathing disorders in adults: recommendations for syndrome definition and measurement techniques in clinical research. The Report of an American Academy of Sleep Medicine Task Force. Sleep 1999; 22:667689.

22. Kauta SR, Keenan BT, Goldberg L, Schwab RJ. Diagnosis and treatment of sleep disordered breathing in hospitalized cardiac patients-a reduction in 30-day hospital readmission rates. J Clin Sleep Med 2014; 10:10519.

23. Mehra R, Benjamin EJ, Shahar E, Gottlieb DJ, Nawabit R, Kirchner L, Sahadevan J, Redline S. Association of nocturnal arrhythmias with sleepdisordered breathing: the Sleep Heart Health Study. Am J Respir Crit Care Med 2006; 173:9106.

24. Foster GD, Sanders MH, Millman R, Zammit G, Borradaile KE, Newman AB, Wadden TA, Kelley D, Wing RR, Sunyer FX, Darcey V, Kuna ST; Sleep AHEAD Research Group. Obstructive sleep apnea among obese patients with type 2 diabetes. Diabetes Care 2009; 32:10171019.

25. Lecube A, Sampol G, Lloberes P, Romero O, Mesa J, Hernández C, Simó R. Diabetes is an independent risk factor for severe nocturnal hypoxemia in obese patients. A case- control study. PLoS One 2009; 4:e4692.

26. Peppard PE, Young T, Palta M, Skatrud J. Prospective study of the association between sleep-disordered breathing and hypertension. N Engl J Med 2000; 342 (19):13781384.

27. Punjabi NM, Caffo BS, Goodwin JL, Gottlieb DJ, Newman AB, O'Connor GT, Rapoport DM, Redline S, Resnick HE, Robbins JA, Shahar E, Unruh ML, Samet JM. Sleep-disordered breathing and mortality: a prospective cohort study. PLoS Med 2009; 6(8):e1000132.

28. Spiegel K, Knutson K, Leproult R, Tasali E, Van Cauter E. Sleep loss: a novel risk factor for insulin resistance and type 2 diabetes. J Appl Physiol 2005; 99:20082019.
29. Guest CB, Park MJ, Johnson DR, Freund GG. The implication of proinflammatory cytokines in type 2 diabetes. Front Biosci 2008; 13:5187 5194.

30. Javid A. Malik, Shariq Rashid Masoodi, Sheikh Shoib. Obstructive sleep apnea in Type 2 diabetes and impact of continuous positive airway pressure therapy on glycemic control. Indian Journal of Endocrinology and Metabolosm 2017; 21(1): 106112.

31. Stratton IM, Adler AI, Neil HA, Matthews DR, Manley SE, Cull CA, Hadden D, Turner RC, Holman RR. Association of glycaemia with macrovascular and microvascular complications of type 2 diabetes (UKPDS 35): prospective observational study. BMJ 2000; 321:405412.

32. Kohner EM Microvascular disease: what does the UKPDS tell us about diabetic retinopathy? Diabet Med 2008; 25(Suppl. 2):2024.

33. Brooks B, Cistulli PA, Borkman M, Ross G, Mcghee S, Grunstein RR, Sullivan CE, Yue DK. OSA in obesenoninsulin-dependent diabetic patients: Effect of CPAP treatment on insulin responsiveness. J Clin Endocrinol Metab 1994; 79:16815.

34. Harsch IA, Schahin SP, Brückner K, RadespielTröger M, Fuchs FS, Hahn Eg, Konturek PC, Lohmann T, Ficker JH. The effect of continuous positive airway pressure treatment on insulin sensitivity in patients with OSAS and type 2 diabetes. Respiration. 2004; 71:2529.

35. Harsch IA, Schahin SP, Radespiel- Tröger M, Weintz O, Jahreiß H, Fuchs FS, Wiest GH, Hahn E, Lohmann T, Konturek PC, Ficker JH. Continuous positive airway pressure treatment rapidly improves insulin sensitivity in patients with OSAS. Am J Respir Crit Care Med 2004; 169:15662. 